\title{
Solid-stemmed spring wheat cultivars give better androgenic response than hollow-stemmed cultivars in anther culture
}

\author{
Dorota Weigt $^{1}$ - Angelika Kiel ${ }^{1} \cdot$ Jerzy Nawracala $^{1} \cdot$ Mateusz Pluta $^{1} \cdot$ Agnieszka Lacka $^{2}$
}

Received: 26 March 2016 / Accepted: 9 November 2016/Published online: 1 December 2016 / Editor: Gregory Phillips

(C) The Author(s) 2016. This article is published with open access at Springerlink.com

\begin{abstract}
Solid-stemmed spring wheat cultivars (Triticum aestivum L.) are resistant to the stem sawfly (Cephus cinctus Nort.) and lodging. Anthers of 24 spring wheat cultivars with varying content of pith in the stem were used in the experiment. All were classified into three groups: solid, mediumsolid and hollow stems. There was considerable influence of the cultivar on callus formation and green plant regeneration. The highest efficiency of green plant regeneration (24\%) was observed for the solid-stemmed AC Abbey cultivar. There was no regeneration from the explants of four cultivars: CLTR 7027, Alentejano, Marquis and Bombona. Principal component analysis showed no differences between the cases under observation (callus induction and green plant regeneration) in their response to pre-treatment temperatures (4 and $\left.8^{\circ} \mathrm{C}\right)$. The examination of the effects of various auxin types in the induction medium on callus formation and green plant regeneration revealed that the strongest stimulation of these processes was observed in the C17 medium with 2,4-D and dicamba. The efficiency of callus formation and green plant regeneration was greater in solid-stemmed cultivars than in hollow-stemmed cultivars.
\end{abstract}

Keywords Androgenesis $\cdot$ Haploid $\cdot$ Spring wheat $\cdot$ Solid stem

Angelika Kiel

akiel@up.poznan.pl

1 Department of Genetics and Plant Breeding, Poznan University of Life Sciences, Poznan, Poland

2 Department of Mathematical and Statistical Methods, Poznan University of Life Sciences, Poznan, Poland

\section{Introduction}

Solid-stemmed wheat is highly resistant to the wheat stem sawfly (Cephus cinctus Nort.) (Weiss and Morrill 1992; Hayat et al. 1995) and lodging (Clarke et al. 2002; Kong et al. 2013). Furthermore, stem solidness improves yield under water-limited conditions by large storage capacity for water-soluble carbohydrates (Pierre et al. 2010). It would be beneficial to introduce genes determining the solid stem trait in well-yielding Polish varieties. The use of androgenesis in the breeding program would shorten the time needed for the development of new lines with a solid stem.

In vitro culture techniques give a possibility to obtain new genetic variability and intensify the process of breeding new varieties of wheat. By increasing the efficiency of haploid plant regeneration and obtaining doubled haploid lines (DH) from them, the breeding cycle would be significantly reduced, particularly in the case of self-pollinated crops such as wheat. It is much easier to analyse the traits of homozygous DH lines, since the phenotype of these plants corresponds to their genotype (Baenziger et al. 2001). Haploid wheat plants may be obtained by androgenesis in anther cultures, isolated microspore cultures, or by crossing with maize (wheat $\mathrm{x}$ maize system) and then by embryo culture (Verma et al. 1999; Niroula and Bimb 2009). The first of these methods has the greatest potential as, in theory, it allows the production of many haploid plants from one anther. However, androgenesis is limited by a strong impact of the donor plant genotype and the influence of external factors on the efficiency of regeneration of haploid green plants (Datta 2005; Forster et al. 2007). Therefore, in wheat breeding, some authors suggest the use of hybrids in which at least one parent has high androgenesis capacity (Bullock et al. 1982; Dağüstü 2008). 
The aim of the present study was to analyse the relationship between the content of pith in the stem of spring wheat cultivars and their capacity to regenerate in anther cultures.

\section{Materials and Methods}

Plant material The pith content in the stem was assessed at the Agricultural Experimental Farm in Dłoń, Poland, in 2012. Twenty-four spring wheat cultivars with varying content of pith in the stem were examined: four Polish cultivars with hollow stems (Arabella, Bombona, Ostka Smolicka and Parabola); 18 accessions from the National Small Grains Collection of the Agricultural Research Service of the United States Department of Agriculture, Aberdeen ID, USA; one cultivar from the Leibniz-Institut für Pflanzengenetik und Kulturpflanzenforschung - Gatersleben (Carola); and one cultivar (AC Abbey) from Dr. Ron DePauw (Agriculture and Agri-Food Canada (AAFC), Semiarid Prairie Agriculture Research Centre, Swift Current, Canada). All cultivars were grown under field conditions. The experiment design was a randomized block with three replicates. To estimate the degree of solidness, 50 individual plants were collected from each plot and cut in the middle of five consecutive internodes. The following 5 -grade scale was used for evaluation: grade 1 -hollow stem- $0 \%$ filled by pith; grade 2, 25\% filled by pith; grade 3,50\% filled by pith; grade $4,75 \%$ filled by pith; and grade 5, $100 \%$ filled by pith. The total value of the content of pith in the stem was the sum of the values from all the internode cuts. For example, a plant with a hollow stem scored 5 points, while one with a completely filled stem scored 25 points.

To compare androgenic responses of cultivars with solid, medium-solid (medium) and hollow stems, all the cultivars were classified into three groups: 5-15, 15.1-20 and 20.1-25 points, respectively.

\section{Preparation of donor plants and pre-treatment of donor} spikes Donor plants for in vitro cultures were grown under field conditions in 2013 at the Experimental Nursery of the Department of Genetics and Plant Breeding, Poznań University of Life Sciences. For in vitro cultures, immature spikes were collected when the flag leaf emerged and when most microspores in the central region of the spikes were at a mid- or late-uninucleate stage. To verify the developmental stage of microspores, one or two anthers from each spike were examined microscopically using acetocarmine staining (Barnabas et al. 2001). Then, half of the spikes were placed in beakers with distilled water at $4^{\circ} \mathrm{C}$ and the other half at $8^{\circ} \mathrm{C}$ in the dark for $8 \mathrm{~d}$ in order to estimate the influence of different cold pre-treatment temperatures on the induction of androgenesis and plant regeneration.
In vitro culture After the cold pre-treatment, spikes were superficially sterilized with $4.85 \%(w / v)$ calcium hypochlorite (Sigma-Aldrich ${ }^{\circledR}$, Poznan, Poland) for $4 \mathrm{~min}$, then washed three times for $5 \mathrm{~min}$ with sterilized, distilled water. Anthers were excised from the spikes in a laminar airflow cabinet, and plated on $50 \times 10 \mathrm{~mm}$ Petri dishes (NOEX, Komorniki, Poland) containing $8 \mathrm{~mL}$ of the solid induction medium. For callus induction, a C-17 medium (Wang and Chen 1983) with modification (Weigt et al. 2012) was used. The medium was solidified with $0.3 \%(w / v)$ Gelrite ${ }^{\circledR}$ (Sigma-Aldrich ${ }^{\circledR}$, St. Louis, MO) and sterilized by autoclaving $\left(121^{\circ} \mathrm{C}, 27 \mathrm{~min}\right.$ and $121.6 \mathrm{kPa}$ pressure). Two combinations of different growth regulators (added pre-autoclaving) were used: (1) $1.0 \mathrm{mg} \mathrm{L}^{-1}$ 2,4-dichlorophenoxyacetic acid (2,4-D ) and $1.0 \mathrm{mg} \mathrm{L}^{-1} 3,6$ dichloro-2-methoxybenzoic acid (dicamba); or (2) $1.5 \mathrm{mg} \mathrm{L}^{-1}$ 2,4-D and $0.5 \mathrm{mg} \mathrm{L}^{-1}$ kinetin (Sigma-Aldrich ${ }^{\circledR}$ ). Fifty anthers from a single spike were cultured in each Petri dish. Four combinations including pre-treatment and growth regulators were used. In each combination, 450 anthers of each cultivar were cultured. Petri dishes were sealed with Parafilm $M \circledR$ (SigmaAldrich $\left(\right.$ ) and incubated at $28^{\circ} \mathrm{C}$ in the dark for 8 to $10 \mathrm{wk}$. Then the calluses were counted and transferred into $50 \times 10 \mathrm{~mm}$ Petri dishes containing $8 \mathrm{~mL}$ of MS regeneration medium (Murashige and Skoog 1962) modified according to Weigt et al. (2012). The MS medium was solidified with $0.6 \%$ $(w / v)$ agar (Sigma-Aldrich $囚)$ and autoclaved as mentioned above. After 4 to $6 \mathrm{wk}$ young, green plantlets obtained on the regeneration medium were transferred to $150 \mathrm{~mL}$ conical flasks (Archem, Kamieniec Wroclawski, Poland) containing $30 \mathrm{~mL}$ of MS regeneration medium (described above) for further growth. Green plantlets with well-formed roots were transplanted to small pots with sterilized soil (2:1 peat/sand mixture), placed in a growth chamber and maintained at $24^{\circ} \mathrm{C}$ with a $16 \mathrm{~h}$ photoperiod at light intensity of about $250 \mu \mathrm{m} \mathrm{m}^{-2} \mathrm{~s}^{-1}$ provided by cool white fluorescent bulb (Zext, Sulejowek, Poland) for acclimatization.

Data analysis The experiments were analysed as a completely randomized designs. There were three replicates of each treatment. To estimate the effect of the cultivar and the influence of different pre-treatment temperatures and hormones in the induction medium, the following traits were determined: the efficiency of callus formation (CF), expressed as the number of calluses produced per 100 anthers; the efficiency of green plant regeneration (GPR), expressed as the number of green plants regenerated per 100 anthers; and the efficiency of albino plants regeneration (APR), expressed as the number of albino plants regenerated per 100 anthers.

Principal component analysis (PCA) was used to illustrate the relationship between the observed variables (callus formation, green and albino plant regeneration) and the replicates of the experiment representing different experimental combinations (Abdi and Williams 2010). This method is commonly 
used in biological studies to reduce the number of variables and to facilitate analysis by eliminating the autocorrelation between them. The analysis enables creation of a mathematical model in a virtual multidimensional space, and along the greatest diversity of the material analysed, it assigns a new set of values of linearly uncorrelated variables (principal components) and thus assigns new coordinates to individual observations. New variables were considered to be synthetic indicators, showing natural features in a spatial dimension. The sums of nine replications obtained for each case were analysed with a program package ggbiplot in $\mathrm{R}$ ( $\mathrm{R}$ Development Core Team 2013).

\section{Results}

Stem solidness The whole range of variability was observed among the plants tested, from solid-stemmed cultivars to those with a hollow stem. Of all the cultivars tested, eight were classified as solid-stemmed. The Polish cultivars used in the experiment were classified as hollow-stemmed. Some cultivars (e.g., Solid Straw Tuscan Varia, Americano 44D, Ruzynska II) that were characterized as solid-stemmed did not exhibit this trait under the environmental conditions of this study. Their scores of solidness were 11.6, 11.5 and 11.3, respectively. All cultivars were divided into three groups according to these data (Table 1).

Table 1. Evaluation of filling stem by pith of 24 spring wheat cultivars

\begin{tabular}{lll}
\hline Group & Genotype & $\begin{array}{l}\text { Stem solidness } \\
\text { evaluation (points) }\end{array}$ \\
\hline \multirow{2}{*}{ Solid } & CLTR 7027 & 23.8 \\
& Carola & 23.6 \\
& Tybalt & 23.3 \\
& Fortuna & 21.5 \\
& Sawtana & 21.34 \\
& AC Abbey & 21.27 \\
Tedium & Tioga & 20.7 \\
& Leda Collection A47 & 20.1 \\
& Glenman & 19.6 \\
& Rescue & 19.2 \\
& Chinook & 18.8 \\
& Alentejano & 18.2 \\
& 431 & 17.7 \\
& 401 & 17.5 \\
Hollow & Marquis & 16.4 \\
& H N ROD 5 13 750 & 15.3 \\
& Arabella & 13.8 \\
& 404 & 13.6 \\
& Solid Straw Tuscan Varia & 11.6 \\
& Americano 44D & 11.5 \\
& Ruzynska II & 11.3 \\
& Ostka Smolicka & 11.1 \\
& Parabola & 11.0 \\
& Bombona & 5.8 \\
\hline
\end{tabular}

The effect of the genotype, pre-treatment of different spikes, hormones used in the induction medium and degree of stem solidness on callus formation and green plant regeneration Calluses were formed after 8 to $10 \mathrm{wk}$ of culturing (Fig. 1). Only the anthers of two cultivars, CLTR 7027 and Bombona, did not form any calluses. The general results of in vitro anther culture are shown in Table 2. A total of 43,200 anthers were plated and 1363 calluses were formed. The average efficiency of callus formation was $3.15 \%$. The highest efficiency of callus induction $(27.78 \%$ ) occurred for the cultivar Rescue on medium with 2,4-D and dicamba. A total of 456 plants were regenerated from 1363 calluses (Fig. 2). About $16 \%$ of them had chlorophyll defects. Green plants were obtained at an average efficiency of $0.88 \%$, which represented a total of 382 plants. The highest efficiency of green plant regeneration (24\%) was observed in the AC Abbey cultivar (solid-stemmed) on medium with 2,4-D and dicamba after cold pre-treatment at $4^{\circ} \mathrm{C}$. Green plants were not regenerated from explants of four cultivars: CLTR 7027, Alentejano, Marquis and Bombona. From the calluses of cultivars 401, Solid Straw Tuscan Varia and Parabola, only albino plants were obtained.

The PCA explained $83.6 \%$ of the total variability of cultivars in variables under analysis (callus formation, green and albino plant regeneration). As results from the vectors of loadings of variables on the first two principal components, there was a strong positive correlation between the callus formation capacity and green plant regeneration. The variables were not correlated with the occurrence of albino plants.

There were no differences between the cases under observation and response to the temperature applied (Fig. 3). Analogous dependences were also observed in concentration ellipsoids made for temperature-dependent experimental combinations of factors. For this reason this factor was omitted in further analysis.

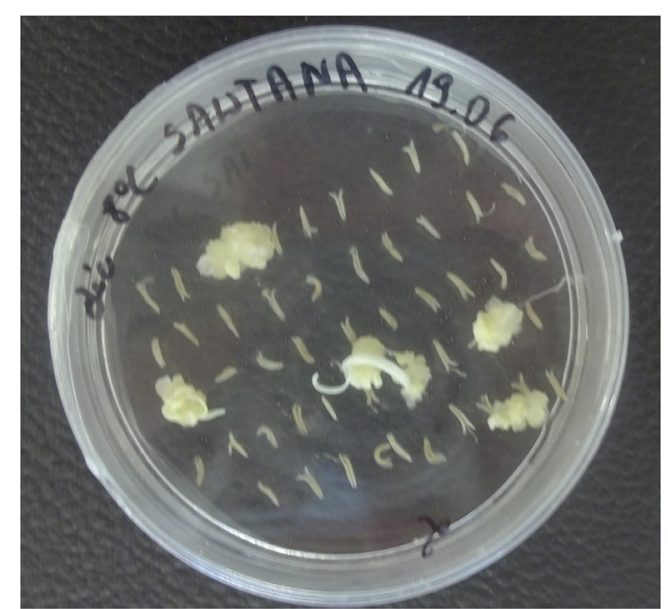

Figure 1. Callus formation from anthers of cv. Sawtana on the induction medium containing 2,4-D and dicamba. 


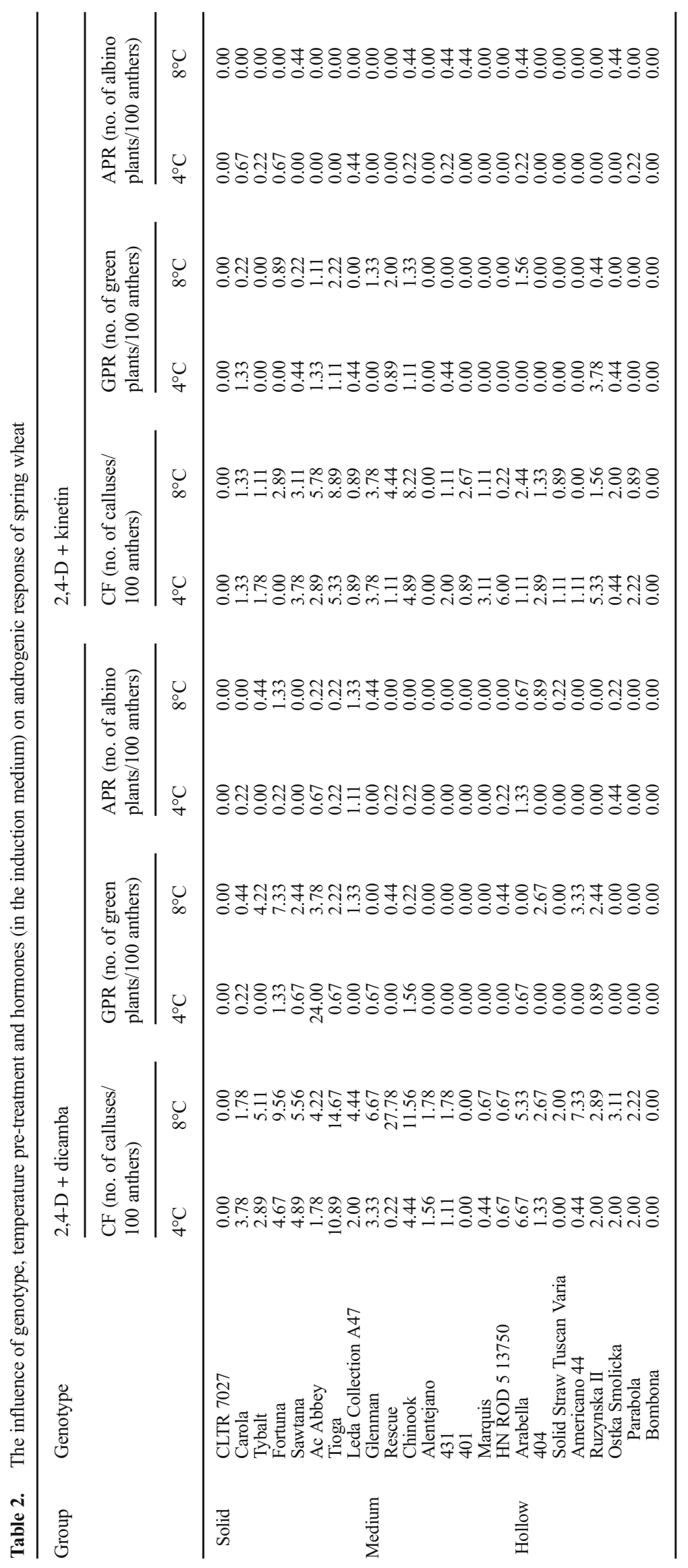




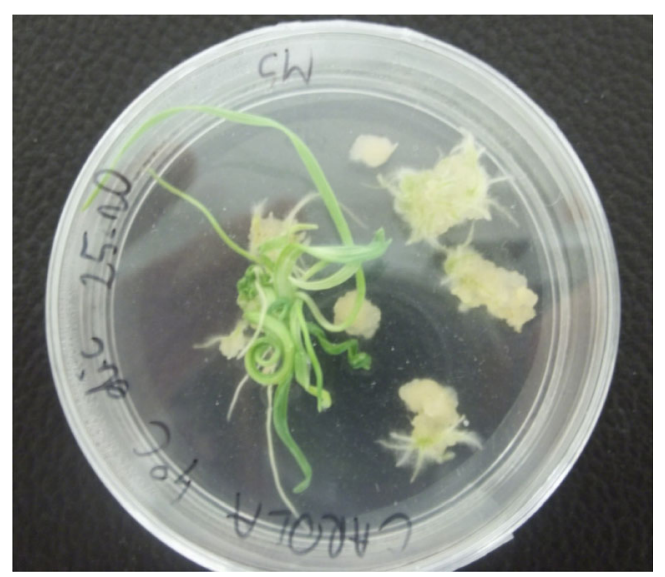

Figure 2. Green plant of cv. Carola regeneration on MS medium.

As far as the division according to the degree of stem solidness and the medium applied is concerned, the most calluses and green plants were obtained from the solid stem on the medium containing 2,4-D and dicamba (Fig. 4). In this combination, calluses were formed most efficiently by three cultivars, Rescue, Tioga and Chinook, with callus tissue formation efficiencies of $27.78,14.67$ and $11.56 \%$, respectively (Table 2). The highest efficiency of green plant regeneration (24 per 100 anthers) was obtained from calluses of the cultivar Ac Abbey on C17 medium with 2,4-D and dicamba. Also, there was high efficiency of green plant regeneration from calluses of the cultivar Fortuna (7.33\%). Hollow and medium cultivars on the medium with 2.4-D and kinetin resulted in similar values of variables, wherein the abundance of green plants in the medium group was higher than in the hollow one.
Anthers of the cultivar Alentejano produced calluses only on the induction medium with 2,4-D and dicamba, while anthers of genotype 401 produced calluses only on the induction medium $\mathrm{C} 17$ with 2,4-D and kinetin. Calluses from four cultivars (Tybalt, HNROD 513750, 404 and Americano 44D) regenerated green plants only on the induction medium with 2,4-D and dicamba. On the contrary, green plants of cultivars 431 and Ostka Smolicka were obtained only from calluses produced on C17 medium with 2,4-D and kinetin. The majority of albino plants occurred for the hollow cultivars on the medium with 2,4-D and dicamba and for solid cultivars on the medium containing 2,4-D and kinetin (Fig. 4).

\section{Discussion}

Solid-stemmed wheat cultivars were developed to minimize losses from wheat stem sawflies and lodging. Cultivar S-615 is the source of solidness of the stem, the presence of which can be found in most of the cultivars from North America. Polish cultivars are characterized by hollow stems, so solidness would be an improvement. To accelerate this process, androgenesis in anther cultures can be used. Unfortunately, the cultivars which are important in agriculture are often recalcitrant in these techniques. Zheng (2003) suggested that the ability to induce androgenesis is an inherited and variable trait. Dağüstü (2008) and Kondić-Špika et al. (2008) suggested that androgenesis should only be applied for breeding combinations in which at least one of the parent lines has high androgenic capacity. Recalcitrant but valuable cultivars

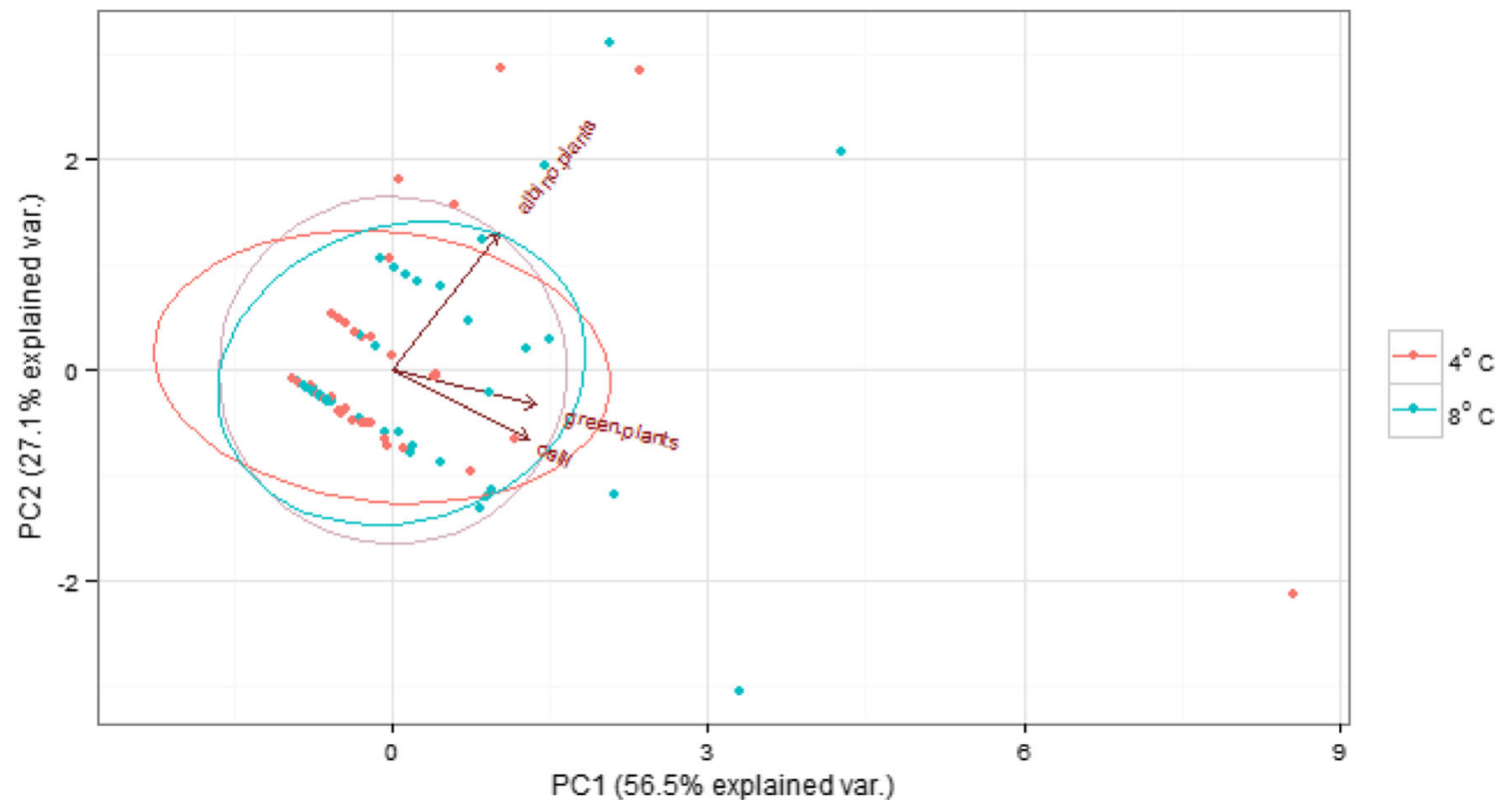

Figure 3. Principal component analysis of the cultivars. Cases are grouped by the applied temperature. Ellipsoids indicate $67 \%$ confidence. 


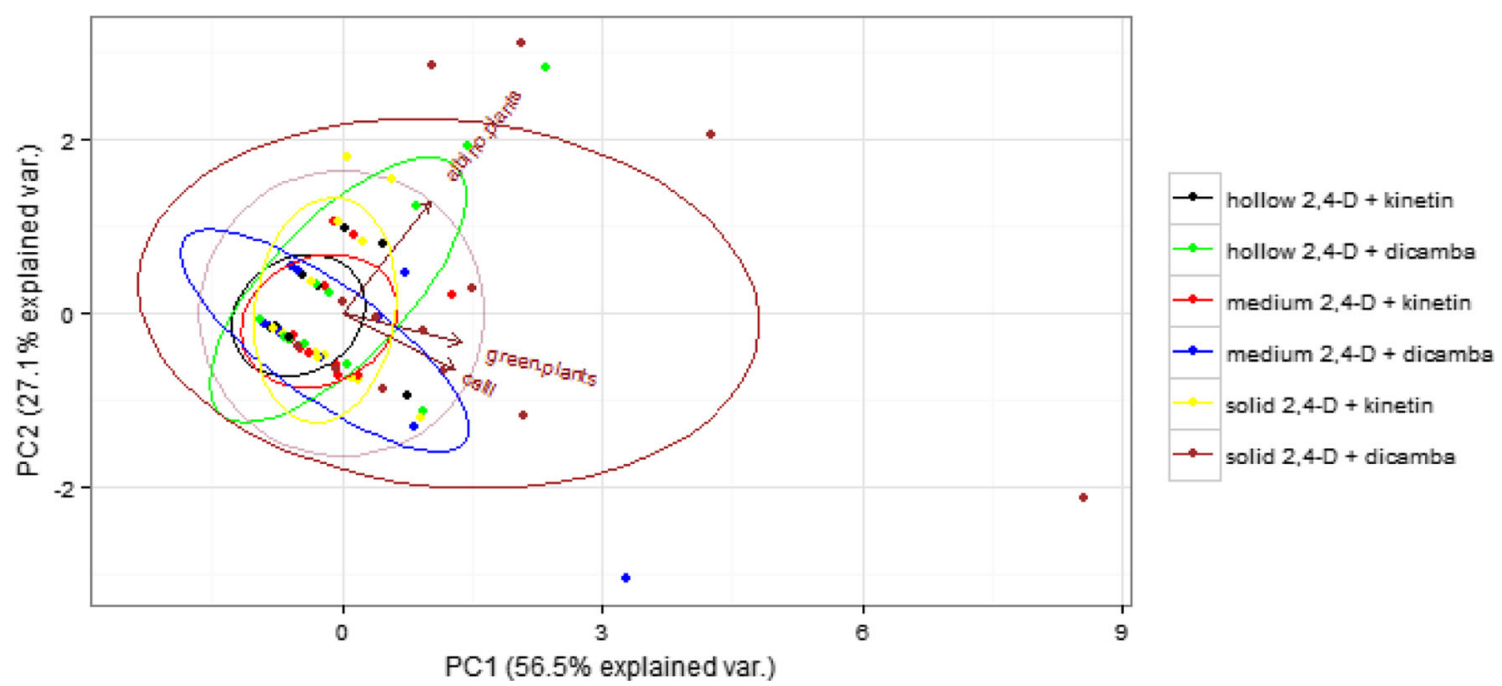

Figure 4. Principal component analysis of the cultivars. Points are grouped by the degree of stem solidness and the medium applied. Ellipsoids indicate $67 \%$ confidence.

can be crossed with varieties which respond to androgenesis well (Kim et al. 2003). Therefore, the ability of genetic improvement by androgenesis may be more useful than the manipulation of external factors (Dağüstü 2008).

The genotype of the donor plant is a major factor influencing the ability to induce androgenesis (Rybczyński et al. 1991; Ayed et al. 2010; Tadesse et al. 2012). The present study confirmed this observation. Among 24 cultivars used in the experiment there were considerable differences both in the callus formation efficiency (ranging from 0 to 27.78\%) and the green and albino plant regeneration (ranging from 0 to $24 \%$ and from 0 to $1.33 \%$, respectively). The best efficiency of green plant regeneration was obtained from AC Abbey cultivar, which served as control across our previous experiments. Similar efficiencies were noted in a previous study on spring wheat cultivars resistant to Fusarium, in which the average regeneration efficiency was genotype-dependent and ranged from 0 to $17.33 \%$ (Weigt et al. 2012).

Despite strong genotypic differences, it is possible to obtain haploid plants through androgenesis even from recalcitrant cultivars by appropriate crossing or by adjustment of pre-treatment conditions and composition of the culture medium (Trottier et al. 1993; Datta 2005; Redha and Talaat 2008). The induction of changes in a microspore development from the gametophytic to sporophytic pathway often requires a stress stimulus. Delaying the mitosis in pollen by cooling or other factors is beneficial to the induction of androgenesis (Śnieżko 1991; Shariatpanahi et al. 2006). Thermal pre-treatment is the most common factor stimulating androgenesis (Murovec and Bohanec 2012). Pre-treatment of spikes at low temperatures $\left(3\right.$ to $10^{\circ} \mathrm{C}$ for 5 to $14 \mathrm{~d}$ ) is the most common method of wheat pollen induction (Śnieżko 1991; Wang et al. 2000). The present study examined the influence of two different cold pre-treatments $\left(4\right.$ and $\left.8^{\circ} \mathrm{C}\right)$ on the induction of androgenesis and green plant regeneration. As the statistical analysis revealed, there were no differences in response between these two temperatures. Similar thermal shock conditions were proposed by El-Hennawy et al. (2011). They applied a cold pre-treatment at $4^{\circ} \mathrm{C}$ for 6 to $8 \mathrm{~d}$ and observed green plant regeneration efficiency of 0 to $10 \%$. Datta (2005) recommends wheat spike treatment at a higher temperature $\left(8^{\circ} \mathrm{C}\right)$ for $10 \mathrm{~d}$.

In most plant species growth regulators are a very important factor stimulating cell division in pollen. An exogenous auxin is necessary to induce androgenesis. The present study showed an almost doubling of callus formation and tripling of green plant formation on a medium supplemented with 2,4-D and dicamba, as compared with a medium supplemented with 2,4-D and kinetin. Satyavathi et al. (2004) also observed the beneficial effect of dicamba. Hassawi et al. (1999) observed the highest callus regeneration on a medium supplemented with 2,4-D and kinetin in comparison with a medium containing 2,4-D and dicamba. It appears that cultivars of various origins can react differently to the composition of hormones in the inducing medium. This assumption is confirmed not only by the referenced publications but also by previous research from this research group (Weigt et al. 2012).

The present study strongly indicates that a relationship between androgenic capacity and stem solidness exists. Solid-stemmed cultivars produced more calluses and regenerated more green plants than the cultivars with a medium or hollow stem. This is the first report about the relationship between the content of pith in the stem and plant androgenic capacity. The interdependence between stem solidness and the capacity to 
induce androgenesis will facilitate the production of new wheat varieties with pith in stems by using in vitro cultures.

Open Access This article is distributed under the terms of the Creative Commons Attribution 4.0 International License (http:// creativecommons.org/licenses/by/4.0/), which permits unrestricted use, distribution, and reproduction in any medium, provided you give appropriate credit to the original author(s) and the source, provide a link to the Creative Commons license, and indicate if changes were made.

\section{References}

Abdi H, Williams LJ (2010) Principal component analysis. Wiley Interdisciplinary Reviews: Computational Statistics 2:433-459

Ayed OS, De Buyser J, Picard E, Trifa Y, Amara HS (2010) Effect of pretreatment on isolated microspores culture ability in durum wheat (Triticum turgidum subsp. durum Desf.). J Plant Breed Crop Sci 2: 30-38

Baenziger S, KM K, Haliloglu K (2001) Wheat in vitro breeding. The world wheat book: a history of wheat breeding. Intercept Limagrain, New York, pp. 979-1000

Barnabas B, Szakacs E, Karsai I, Bedö Z (2001) In vitro androgenesis of wheat: from fundamentals to practical application. Euphytica 119: 211-216

Bullock WP, Baenziger PS, Schaeffer GW, Bottino PJ (1982) Anther culture of wheat (Triticum aestivum L.) F1's and their reciprocal crosses. Theor Appl Genet 62:155-159

Clarke FR, Clarke JM, Knox RE (2002) Inheritance of stem solidness in eight durum wheat crosses. Can J Plant Sci 82:661-664

Dağüstü N (2008) Diallel analysis of anther culture response in wheat (Triticum aestivum L.). Afr J Biotechnol 7:3419-3423

Datta SK (2005) Androgenic haploids: factors controlling development and its application in crop improvement. Curr Sci 89:1870-1878

El-Hennawy MA, Abdalla AF, Shafey SA, Al-Ashkar IM (2011) Production of doubled haploid wheat lines (Triticum aestivum L.) using anther culture technique. Ann Agric Sci 56:63-72

Forster BP, Heberle-Bors E, Kasha KJ, Touraev A (2007) The resurgence of haploids in higher plants. Trends Plant Sci 12:368-375

Hassawi D, Qi J, Liang GH (1999) Effects of growth regulator and genotype on production of wheat and triticale polyhaploids from anther culture. Plant Breed 104:40-45

Hayat MA, Martin JM, Lanning SP, McGuire CF, Talbert LE (1995) Variation for stem solidness and its association with agronomic traits in spring wheat. Can J Plant Sci 75:775-780

Kim KM, Baenziger PS, Rybczyński JJ, Arumuganathan K (2003) Characterization of ploidy levels of wheat microspore-derived plants using laser flow cytometry. In Vitro Cell Dev Biol Plant 39:663-668

Kondić-Špika AD, Kobiljski BD, Hristov NS (2008) Efficiency of anther culture technique in the production of wheat double haploids. Proc Nat Sci Matica Srpska Novi Sad 115:35-40
Kong E, Liu D, Guo X, Yang W, Sun J, Li X, Zhan K (2013) Anatomical and chemical characteristics associated with lodging resistance in wheat. Crop J 1:43-49

Murashige T, Skoog F (1962) A revised medium for rapid growth and bioassays with tobacco tissue cultures. Physiol Plant 15:473-497

Murovec J, Bohanec B (2012) Haploids and doubled haploids in plant breeding. Plant Breed 5:87-106

Niroula RK, Bimb HP (2009) Overview of wheat x maize system of crosses for dihaploid induction in wheat. World Appl Sci J 7: $1037-1045$

Pierre C, Trethowan R, Reynolds M (2010) Stem solidness and its relationship to water-soluble carbohydrates: association with wheat yield under water deficit. Funct Plant Biol 37:166-174

R Development Core Team (2013) R: a language and environment for statistical computing. R Foundation for Statistical Computing, Vienna

Redha A, Talaat A (2008) Improvement of green plant regeneration by manipulation of anther culture induction medium of hexaploid wheat. Plant Cell Tiss Organ Cult 92:141-146

Rybczyński JJ, Simonson RL, Baezinger PS (1991) Evidence for microspore embryogenesis in wheat anther culture. In Vitro Cell Dev Biol Plant 27:168-174

Satyavathi VV, Jauhar PP, Elias EM, Rao MB (2004) Effects of growth regulators on in vitro plant regeneration in durum wheat. Crop Sci 44:1839-1846

Shariatpanahi ME, Bal U, Heberle-Bors E, Touraev A (2006) Stresses applied for the re-programming of plant microspores towards in vitro embryogenesis. Physiologia Plant 127:519-534

Śnieżko R (1991) Anthers and pollen cultured in vitro culture. Wiad Botan 35:23-33

Tadesse W, Inagaki M, Tawkaz S, Baum M, Van Ginkel M (2012) Recent advances and application of doubled haploids in wheat breeding. Afr J Biotechnol 11:15484-15492

Trottier MC, Collin J, Comeau A (1993) Comparison of media for their aptitude in wheat anther culture. Plant Cell Tiss Organ Cult 35:5967

Wang M, Van Bergen S, Van Duijn B (2000) Insights into a key developmental switch and its importance for efficient plant breeding. Plant Physiol 124:523-530

Wang P, Chen Y (1983) Preliminary study on production of height of pollen $\mathrm{H} 2$ generation in winter wheat grown in the field. Acta Agron Sin 9:283-284

Weigt D, Nawracała J, Popowska D, Nijak K (2012) Examination of ability to androgenesis of spring wheat genotypes resistant to Fusarium. BioTechnologia J Biotechnol Comp Biol Bionanotechnol 93:116-122

Weiss MJ, Morrill WL (1992) Wheat stem sawfly (Hymenoptera: Cephidae) revisited. Am Entomol 38:241-245

Verma V, Bains NS, Mangat GS, Nanda GS, Gosal SS, Singh K (1999) Maize genotypes show striking differences for induction and regeneration of haploid wheat embryos in the wheat $\times$ maize system. Crop Sci 39:1722-1727

Zheng MY (2003) Microspore culture in wheat (Triticum aestivum) doubled haploid production via induced embryogenesis. Plant Cell Tiss Organ Cult 73:213-230 